New perspectives on Eighteen Degree Water formation in the North Atlantic

Terrence M. Joyce

Prepared for a special issue of Journal of Oceanography by

Terrence M. Joyce

Woods Hole Oceanographic Institution

360 Woods Hole Rd., Mail Stop 21

Woods Hole, MA USA 02543

tjoyce@whoi.edu

8 April 2011 


\begin{abstract}
In this report, Eighteen Degree Water (EDW) formation will be discussed, with emphasis on advances in understanding emerging within the past decade. In particular, a recently completed field study of EDW (CLIMODE) is suggesting that EDW formation within a given winter can have at least two different dominant physics and distinct locations: one type formed in the northern Sargasso Sea, largely away from the strong flows of the Gulf Stream where 1D physics may apply, and a second type formed along the southern flank of the Gulf Stream, in a region where the background vorticity of the flow and cross-frontal mixing plays a key role in the convective formation process.
\end{abstract}

\title{
Introduction
}

The subtropical mode water of the North Atlantic Ocean was first identified as having remarkably uniform properties in temperature $\left(17.9 \pm 0.3{ }^{\circ} \mathrm{C}\right)$ and salinity $(36.50 \pm 0.10$ psu) by Worthington (1959), who named it Eighteen Degree Water (EDW), a name which has persisted over time. It is very evident in volumetric atlases from hydrographic data (Wright and Worthington 1970) and here using the modern gridded WOCE-era electronic atlas (Gouretski and Koltermann 2004, herein Fig. 1). One distinct 'mode' of this $2 \mathrm{D}$ histogram of waters warmer than $7{ }^{\circ} \mathrm{C}$ in the N. Atlantic is clearly the EDW identified by Worthington. Mode Waters as a generic entity (Hanawa and Talley 2001) exist in all the major ocean basins and represent pervasive water masses that can be detected throughout the year both locally, where they are formed, and in locations far from the formation site(s). Worthington identified the Sargasso Sea as the location where EDW could be readily found and the northern reaches of the Sargasso Sea, just south of the separated Gulf Stream as the region of formation. Formation has generally been determined by where the mode water is seen to outcrop at the ocean surface in late winter. Worthington refined his ideas about EDW in a later study (Worthington 1976) where he associated the formation with the large mean negative oceanic heat flux to the atmosphere. At the time, the information about ocean/atmosphere exchange was limited to rather coarse summaries from available 
shipboard data collected over time, and was clearly affected by limited sampling during periods of maximum exchange. These early summaries by Budyko (1963) and Bunker (1976) painted the first basin wide picture of air-sea exchange. Worthington argued that the mean heat loss region over the separated Gulf Stream (GS) was responsible for transforming subtropical waters into EDW, whereas Warren (1972) argued that the region where EDW was 'formed', near $35 \mathrm{~N}, 60 \mathrm{~W}$ was one of zero net heat loss leading him to conclude that EDW formation was the process by which the locallyformed seasonal thermocline was removed during winter: something that occurs in the absence of strong advection and requiring no net heat loss when averaged over the year. Confounding these early ideas about EDW formation was the problem inherent in estimating heat exchange over the ocean, where short- and long-wave radiation measurement were few, and estimates of turbulent exchange of sensible and evaporative heat were limited by both data and models of turbulent exchange over the ocean.

Walin's (1982) ideas about direct estimation of water mass formation using air sea exchange data were a major boost to the field, yet application to EDW formation (eg. Speer and Tziperman 1992, Maze et al. 2009) yielded greatly different estimates of EDW formation. This has prompted a concerted effort to collect field observations and conduct modeling studies to better understand the different physical processes in the ocean associated with water mass formation (advection, subduction, mixing) and better parameterize turbulent exchanges with the atmosphere in the northern Sargasso Sea: this experiment was called CLIMODE (CLIvar MOde water Dynamics Experiment, The Climode Group 2009). In this update, an attempt will be made to summarize what we know about EDW since the review of Hanawa and Talley (2001), including the recently published results from CLIMODE. However, much of the CLIMODE analysis has yet to appear in print and it is expected that this review would be quite different if written a few years from now. It is hoped that enough of the recent thinking will show where advances are to be expected and will serve as a current assessment for EDW, to be contrasted with major contemporary efforts (reported elsewhere in this collection) on Mode Waters found in other ocean basins. 


\section{EDW definitions}

To begin, it is instructive to see how one might define EDW in order to then estimate budgets of how much of it there is and where it is formed. Worthington (1976, table 6) noted that while there were approximately $2512 \times 10^{3} \mathrm{~km}^{3}$ of EDW (waters with temperatures between 17 and $19^{\circ} \mathrm{C}$ ) in the N. Atlantic, if one looked in the North American Basin (west of the mid-Atlantic Ridge), the volume was reduced to $1763 \mathrm{x}$ $10^{3} \mathrm{~km}^{3}$. Siedler et al. (1987) have since shown that a substantial mode water having temperatures of ca. $18^{\circ} \mathrm{C}$ is formed every winter in the North African Basin, near the island of Madeira. This flavor of SubTropical Mode Water was called Madeira Mode Water. Unlike its counterpart in the Sargasso Sea, by the end of summer heating, there is little evidence for a homogeneous thermostad, or region of reduced vertical temperature gradient: it has vanished into the seasonal thermocline (Siedler et al., Fig. 9). If one confines oneself to the region west of the mid-Atlantic Ridge one can limit the contribution of this eastern basin water mass from the census.

The EDW volume can further be refined by estimating the anomaly due to the reduced temperature gradient of EDW imbedded in the permanent thermocline. Worthington (1976, table 8) did this for the western North Atlantic by subtracting the volume of 16$17{ }^{\circ} \mathrm{C}$ water and $19-20{ }^{\circ} \mathrm{C}$ water from that of $17-19{ }^{\circ} \mathrm{C}$ water in his census and found that the EDW volume for the western N. Atlantic was further reduced by about $50 \%$ to $889 \times 10^{3} \mathrm{~km}^{3}$ : thus for one author alone, published estimates of EDW volume differ by a factor of 3 depending on its definition! The last EDW volume estimate is quite close to one based on T/S criteria presented below. Others have tried looking at anomalies of EDW by limiting to those waters having temperature gradient less than some limiting value (eg. Kwon and Riser 2004) or some limiting planetary Potential Vorticity appropriate to the thermocline. Here we use both temperature and salinity constraints and find based on Fig. 1, the volume of EDW between 17.5 and $18.5{ }^{\circ} \mathrm{C}$ with bounding salinities of 36.4 and 36.6 psu is $912 \times 10^{3} \mathrm{~km}^{3}$; so the addition of a salinity criterion and tightening up the temperature definition reduces the overall N. Atlantic numbers substantially. As a check on the new climatological data, the total volume was 
calculated with the WOCE-era atlas without salinity constraints and estimated for 17:19 ${ }^{\circ} \mathrm{C}$ waters to be $2237 \times 10^{3} \mathrm{~km}^{3}$, within the error bars of the Forget et al. (2011) figure of $2360 \times 10^{3} \mathrm{~km}^{3}$, and slightly less than Worthington's given above. Clearly, a tightened temperature definition and the use of salinity for defining the EDW volume (present work) makes a substantial difference. Limiting the spatial domain (western basin) and requiring the local temperature gradient to be less than some reference value are the two principle issues that need further resolution in the literature in the definition of EDW volume. Resulting EDW volume estimates are clearly dependent on the definitions and thus arises the potential for conflicting claims on volumes, formation rates, and ventilation timescales, as we will see later.

Talley and Raymer (1982) first pointed out that there were spatial variations of EDW within a given winter and that there was considerable year to year variability in the thickness and other properties at Bermuda. Joyce et al (2000) showed that interannual variations of EDW PV as observed at Bermuda were well-correlated with the NAO (with no lag/lead), suggesting that changes in air-sea forcing as reflected in major climate indices were important to newly-formed EDW observed at Bermuda. Since EDW is not locally formed near Bermuda in most winters, its time of arrival there has been estimated as a few to several months after formation by using oxygen (eg. Jenkins 1982) or PV (Talley and Raymer 1982, Phillips and Joyce 2007). We will return later to the issue of spatial variations of EDW formed in a given winter with some new data drawn from CLIMODE. Because newly-formed EDW is highly saturated in dissolved oxygen, Jenkins and Goldman (1985) were able to study biological processes affecting EDW oxygen consumption after subduction by calibrating change against 'true' age determined from tritium/helium-3.

As was shown by Schmitz (1996, Fig. 1-21) the southern re-circulation gyre of the GS occupies the region bounded by a box with lat./long. corners at $(40 \mathrm{~N}, 50 \mathrm{~W})$ and $(30 \mathrm{~N}, 55 \mathrm{~W})$ to the east and $(35 \mathrm{~N}, 75 \mathrm{~W})$ and $(25 \mathrm{~N}, 75 \mathrm{~W})$ to the west. This roughly agrees with the float-based circulation on the $26.5 \mathrm{~kg} \mathrm{~m}^{-3}$ surface by Kwon and Riser (2004) reproduced here (Fig. 2). The float trajectories were used to map out the geostrophic pressure on an isopycnal associated with EDW. Data for this circulation map are drawn 
from a period from 1998 to 2002 . The $60 \mathrm{~cm}$ contour (Fig. 2) roughly delineates the southern GS re-circulation gyre identified by Schmitz (1996, Fig. 1-21). Clearly the mean circulation is defining or being defined by the presence of EDW, which is largely contained within this region based on anomaly calculations using a reference vertical temperature gradient. The WOCE mean climatology atlas was used to examine subtle water mass variations of EDW in the Sargasso Sea (Fig. 2, right panel). One can see that saltier (and also warmer - not shown) varieties of EDW are found within the recirculation center, while fresher (and colder) varieties surround them, with a clear tendency for fresher values along the northern boundary in proximity to the Gulf Stream. Since this representation includes all seasons, the wintertime properties are obscured, especially the thickness, which is reduced due to restratification.

\section{Annual EDW budgets \& formation}

EDW formation budgets using the 'Walin' method have been nicely exemplified by Forget et al. (2011) for the three year period 2004 - 2006, inclusive. Various data sets (eg. SST, SSH, Argo floats) have been assimilated in a 1x1 degree lat/lon resolution numerical model that has 16 month, overlapping annual cycles for the above period. Estimates for air-sea exchange have been examined with the inverse machinery and 'adjusted' when necessary to reduce model/data misfits. The resulting annual EDW cycle has been compared with more traditional, float-based estimates of EDW volumes during the same period. The region considered is the entire N. Atlantic as reflected in surface areas and volumes in various temperature classes with 1 degree $\mathrm{K}$ resolution; there was no attempt to stratify the calculation using salinity or surface salinity forcing. The amount of EDW formed annually during the winter months is estimated to be 8.6 $\pm 1.8 \mathrm{Svy}\left(1 \mathrm{Svy}=31.5 \times 10^{3} \mathrm{~km}^{3}\right)$, where they have been able to account for the effects of subgridscale mixing in the model, which actually acts to increase EDW formation during winter, though reducing EDW formation during the remainder of the year. A previous estimate on the amount of EDW production in winter (Kwon and Riser) of 3.5 \pm 0.5 Svy was based on increases in EDW volume during winter from hydrographic 
data alone. While the error bars of the two different estimates don't overlap, they are remarkably close considering that the EDW definition criteria chosen by Kwon and Riser focuses on the western N. Atlantic region and satisfies a constraint that the vertical temperature gradient be less than some maximum value, which we saw earlier gave a factor of 3 reduction in EDW volume by a single author (Worthington 1976). Yet both cited works define EDW formation based on volume increases in winter - so how volume is defined is inherent to estimates of annual formation. While the Kwon and Riser calculation is independent of air-sea forcing, relying only on changes in EDW volume based on hydrography, the Forget et al. calculation is not. So we need to address the sensitivity of 'formation' rates to the input air-sea fluxes.

Wintertime air-sea heat loss over the region of EDW formation can be o $\left(300 \mathrm{Wm}^{-2}\right)$ with uncertainties of o(10\%). Joyce et al (2011) have shown that the maximum of winter heat and water loss in the N. Atlantic is located exactly over the location of the meandering, separated GS, with the warm core of the GS defining the region of largest ocean-atmosphere exchange in winter. During the period of CLIMODE (Feb/Mar 2007, Fig. 3) the winter mean SST field indicates that after traversing the region from $75 \mathrm{~W}$ to $55 \mathrm{~W}$, the warm surface core water of the GS eventually disappears. If one were to choose the 17.5 and $18.5^{\circ} \mathrm{C}$ isotherms for the Walin-type formation analysis, it would be clear (Fig. 3) that the domain would multiply-connected and that $10 \%$ errors in the surface heat flux together with the sensitivity in flux products to spatially dependent air-sea temperature and humidity differences could lead to substantial differences in water mass formation calculations. Forget et al. show that, depending on the flux product used, EDW volume increases during winter range from 5 to 13 Svy based on the Walin-type calculation alone. Because their EDW calculation was constrained by ocean data, air-sea exchange forcing is adjusted to give a better model/data fit and therefore given a reality check that the unconstrained range of estimates lacks. The annual EDW formation rate of ca. 13 Svy by Speer and Tziperman (1992, Table 1) is at an extreme limit of this Walin-type calculation, although the authors made an effort to do the formation calculation in density rather than temperature space, taking into account freshwater forcing. Presumably a constrained estimate of this calculation using Argo float salinities and newer flux estimates might be done in the near future. For 
present, it would therefore seem that the range of EDW formation of 3.5-8.6 Svy between the two previously cited estimates of formation based on temperature must be due to EDW definition. Forget et al. estimate that the principle agents for dissipation of EDW are air-sea exchange in the warm months, leading to formation of a surface thermocline, and cross-frontal mixing of EDW with higher PV waters, principally found to the north of the Gulf Stream. One final comment related to air-sea exchanges, the CLIMODE program offered some unique extensions for improving the parameterization of fluxes using bulk formulae. With high winds and large air-sea temperature differences, and with clear problems with the algorithms at wind speeds above $15 \mathrm{~ms}^{-1}$ (The Climode Group 2009), the expected changes to bulk formulae should improve future estimation of turbulent air-sea fluxes for both heat and water.

\section{Multiple types of EDW formed annually}

Examination of the outcrop window for EDW (Fig. 3) during CLIMODE indicates two possible scenarios for EDW formation. The first is in the region from $73^{\circ} \mathrm{W}: 60^{\circ} \mathrm{W}$ at a latitude near $35^{\circ} \mathrm{N}$. Here in the northern Sargasso Sea and well south of the GS flow, EDW can be seen at the surface. The vertical characteristics of the water are portrayed (Fig. 4) at 3 selected CTD stations from the Knorr cruise in 2007. Station 7, taken in the 'upstream' region within the warm surface core of the GS, shows a strong stratification near the surface and evidence for tropical Salinity Maximum Water (see Worthington 1976, Wüst 1936) with an elevated salinity at a pressure of ca. 200 dbars. Below this layer, a region of reduced stratification, 'old EDW" can be seen with oxygen saturation values below 90\%. In the northern Sargasso Sea (Station 69), a homogeneous water mass, 'new EDW' can be seen between 100 and 400 dbar pressures with elevated oxygen content, a temperature slightly above $18{ }^{\circ} \mathrm{C}$, and a salinity of about $36.6 \mathrm{psu}$. A warmer, less dense surface layer has capped the EDW, likely due to restratification in the presence of lighter surrounding waters. This is also suggested by the lack of an outcrop of the EDW layer near the location of the station (Fig. 3). The salinity of this EDW looks roughly like that of the vertically mixed version of the incoming waters, 
exemplified by station 7. In contrast, the downstream station near the GS (station 50) is located in the other EDW outcrop zone which hugs the GS until about 55W where it erupts from the front and fills the region to the south. This EDW is colder and fresher. Joyce et al (2011) argue that formation of EDW within the frontal region entrains cooler, fresher waters across the GS front from the north and results in a lower salinity, and slightly colder version of EDW. Both types of EDW are highly saturated in oxygen and represent differing types of EDW formed in the same year, as was first noted by Talley and Raymer (1982), who speculated that EDW variations occurred west to east as the EDW further circulated under the strong surface cooling and thus got progressively cooler. According to Joyce et al (2011), the high heat loss region of the GS front is also one in which evaporation exceeds precipitation, making air-sea exchange a candidate for increasing EDW salinity in the region, not decreasing it. By invoking the need for lateral mixing across the GS front $\left(\kappa \sim 100 \mathrm{~m}^{2} \mathrm{~s}^{-1}\right)$, Joyce et al. (2011) were able to satisfy both the downstream advective budgets for salinity and heat for the EDW formed in the GS, clearly indicating that EDW formed along the GS would necessarily be fresher (and colder) than that found forming further to the south and west. The cooling and freshening of the northern version of EDW is affected by cross-frontal exchange and this is reflected in the mean property changes in the hydrography (Fig. 2, right panel). Forget et al. did not include salinity in their budget calculations, but found that cross-frontal mixing in winter could actually enhance EDW production. With salinity, it would have been clear that this new component of EDW formation introduced lower salinity water into the region and affected mean EDW properties of temperature and salinity in the northern Sargasso Sea.

It would seem that the two different types of EDW observed in 2007 represent the end points of the disparate formation hypotheses of Worthington $(1959,1976)$ and Warren (1972): frontal formation under the strong air-sea cooling region (Worthington) and formation in the northern Sargasso Sea away from strong advection and cooling (Warren). Thus, the mean properties of EDW are saltier (Fig. 2, right panel) and warmer within the center of the southern recirculation gyre, where Warren argued for one non-advective endpoint for EDW formation. Worthington's (1972) circulation 
schematic for northward surface flow into the formation region and southward spreading of new EDW away from the region are reasonable if interpreted in density space rather than depth space: lighter waters advect northward and eastward in the GS and are cooled and (slightly) freshened. They become detached from the GS and spread southward to the east of $60 \mathrm{~W}$ where the southern re-circulation gyre detrains fluid southward from the GS (Fig. 2) and spreads this fresher and cooler version of EDW around the edges of the recirculation gyre. How much of the EDW formation occurs in the two regions remains to be determined. Joyce et al (2011) estimated that ca. 1.9:3.2 Svy were formed in the GS flow during 2007, which amounts to either 50:90 \% of the total according to Kwon and Riser, or 22:37 \% if one uses the Forget et al. estimate for annual EDW formation. Other CLIMODE data sets, such as Argo floats having salinity sensors, should be able to address this point as well.

The formation of EDW within the GS represents a new paradigm for mode water formation, one in which the strong lateral and vertical shear of the flow alters convective processes and allows for symmetric and inertial instabilities (Joyce et al. 2009, Thomas et al. 2011). Regions of negative potential vorticity are still formed by cooling, but along front wind stress is also an important contributor to the forcing as denser fluid is advected by winds equatorward across the front (Thomas 2005). The forced, slantwise convection can have lateral scales of only a few $\mathrm{km}$ and is not easily observed except in sub-mesoscale resolving surveys using devices like Seasoar (Fig. 5) during CLIMODE. The entire region between 30 and $110 \mathrm{~km}$ along the undulating track is filled with new EDW, but closer inspection reveals some of the distinctive finestructure of the formation: note the subtle changes in oxygen and fluorescence along the track as one passes through waters recently near the surface (elevated values of these tracers) and waters likely to be upwelling from below (lower tracer concentrations). The entire ventilation process is different from 1D convection and is poorly parameterized in models not resolving the sub-mesoscale, and poorly sampled in most ocean observations. 


\section{Some concluding thoughts and challenges}

Were the formation rates and volumes of EDW well established, one could take the ratio of the two to estimate the ventilation rate for EDW: how much of it is ventilated in a typical year. An independent estimate of this was attempted by Jenkins (1982) using tritium/helium-3 dating at Bermuda: the EDW estimate is difficult to extract from his figures because the age change is large with potential density, and the potential density resolution, limited by discrete sampling bottles, is not good for low potential densities (like for EDW) : an upper limit is 8.5 years (for $\sigma_{\theta}=26.5$ ) from Jenkins (1982, Table 1) and 3 years (Jenkins and Goldman 1985, Fig. 9. depth ca. 230m), which defines a range nearly identical to that between Kwon and Riser's estimate of 3.6 years and the Forget et al. value of 8.7 years. Thus, independent tracer ages do not seem to offer a way out of this conundrum at present. While we have identified at least two types of EDW formed within a given year, we have not yet ascertained which of the two types is dominant in the annual budget.

The issue of the fate of EDW after formation has not been addressed yet with CLIMODE data. One might expect some revised mean circulation update on that offered in Figure 2, left panel, and some assessment of the role that eddies play in the spreading and homogenization of EDW from the formation region. One can also expect some future assessment of how representative the CLIMODE period is compared to past winters. Joyce et al (2011) noted that air-sea exchange during the winter of 2007 was larger over the region than the mean of the previous 19 years. This has not been translated into EDW formation or circulation at this stage and thus represents another aspect of EDW dynamics that may yet emerge from our recent field program. Finally, we should anticipate that comparative dynamics will emerge for EDW and its close kin, North Pacific SubTropical Mode Water, found immediately to the south of the separated Kuroshio.

\section{Acknowledgements}

Thanks are due to all my colleagues in the CLIMODE project, to the National Science Foundation, for its support to the author (OCE 0959387), to the editors of this special 
issue of Journal of Oceanography for inviting this contribution, and to Jane DunworthBaker, who prepared many of the figures in this manuscript. 


\section{References}

Budyko, M.I., 1963. Atlas of heat balance of the world (in Russian). Glav. Geofiz. Obo, Moscow, 69 pp. Translation by I.A. Donehoo, Weather Bureau, WB/T106, Washington, DC, $25 \mathrm{pp}$.

Bunker, Andrew F., 1976. Computations of surface energy flux and annual air-sea interaction cycles of the North Atlantic Ocean. Monthly Weath. Rev., 104, 11221140.

Forget, G. G. Maze, M. Buckley, and J. Marshall, 2011. Estimated Seasonal Cycle of North Atlantic Eighteen Degree Water Volume, J. Phys. Oceanogr., 41, 269-286. doi: 10.1175/2010JPO4257.1

Gouretski, V.V., and K.P. Koltermann, 2004. WOCE Global Hydrographic Climatology, Berichte des Bundesamtes für Seeschifffahrt und Hydrographie, 35/2004. 52 pp.

Hanawa, H. and L. Talley, 2000. Mode Waters, in 'Ocean Circulation and Climate' Edited by J. Siedler, J. Church and J. Gould. Academic Press, pp 373-386.

Jenkins, W.J., 1982. Tritium and 3He in the Sargasso Sea, J. Mar. Res., 40, supplement, 533-569.

Jenkins, W.J., and J.C. Goldman, 1985. Seasonal cycling and primary production in the Sargasso Sea, J. Mar. Res., 43, 465-491.

Joyce, Terrence M., Clara Deser, and Michael A. Spall, 2000. On the relation between decadal variability of Subtropical Mode Water and the North Atlantic Oscillation. J. Climate, 13, 2550-2569.

Joyce, T.M., L.N. Thomas, and F. Bahr, 2009. Wintertime observations of Subtropical Mode Water formation within the Gulf Stream, Geophys. Res. Lett., 36, L02607, doi:10.1029/2008GL035918 
Joyce, T.M., L.N. Thomas, W.K. Dewar, J.B. Girton, 2011. Eighteen Degree Water Formation within the Gulf Stream: a new paradigm arising from CLIMODE, DeepSea Research II, accepted.

Kwon, Y.-O. and S.C. Riser, 2004; North Atlantic Subtropical mode Water: A history of ocean-atmosphere interaction 1961-2000. Geophys. Res, Lett., 31, L19307, doi:10.1029/2004GL021116.

Maze, G., G. Forget, M. Buckley, J. Marshall, and I. Cerovecki, 2009: Using transformation and formation maps to study the role of air-sea heat fluxes in North Atlantic Eighteen Degree Water formation. J. Phys. Oceanogr., 39, 1818-1835.

Phillips, Helen E., and Terrence M. Joyce, 2007. Bermuda's Tale of Two Time Series: Hydrostation S and BATS, J. Phys. Oceanogr., 37, 554-571.

Schmitz, W.J. Jr., 1996. On the Worl Ocean Circulation: Vol. I, Some Global Features/North Atlantic Circulation. WHOI Technical Report WHOI-96-03, 150 pp.

Siedler, G., A. Kuhl, and W. Zenk, 1987. The Madeira Mode Water, J. Phys. Oceanog., 17, 1561-1570.

Speer, K. and E. Tzipermann, 1992. Rates of Water Mass Formation in the North Atlantic Ocean, J. Phys. Oceanog., 22, 93-104.

Talley, L.D., and M.E. Raymer, 1982. Eighteen Degree Water variability. J. Mar. Res., 40, supplement, 757-775.

The Climode Group, 2009. Observing the cycle of convection and restratification over the Gulf Stream system and the subtropical gyre of the North Atlantic ocean: preliminary results from the CLIMODE field campaign, Bull. Amer. Meteor. Soc., 90, 1337-1350. 
Thomas, Leif N., John Taylor, and Terrence M. Joyce, 2011, submitted. Symmetric Instability in the Gulf Stream, Deep-Sea Research II, submitted.

Thomas, L. N., 2005: Destruction of potential vorticity by winds.

J. Phys. Oceanogr., 35, 2457-2466.

Walin, G., 1982: On the relation between sea-surface heat flow and thermal circulation in the ocean. Tellus, 34, 187-185.

Warren, Bruce A., 1972. Insensitivity of subtropical mode water characteristics to meteorological fluctuations. Deep-Sea Res., 19, 1-19.

Worthington, L.V., 1959. The $18^{\circ}$ water in the Sargasso Sea. Deep-Sea Res., 5, 297305.

Worthington, L.V., 1972. Negative Oceanic Heat Flux as a Cause of Water-Mass Formation. J. Phys. Oceanog., 2, 205-211.

Worthington, L.V., 1976. On the North Atlantic circulation. Johns Hopkins Oceanographic studies, The Johns Hopkins Univ, Press., 110 pp.

Wright, W.R., and L.V. Worthington, 1970. The water masses of the North Atlantic Ocean: a volumetric census of temperature and salinity. Ser. Atlas Mar. Envir., 19, 8 pp, 7 plates.

Wüst, Georg, 1936. Oberflächensalzgehalt, Verdunstung, und Niederschlag auf dem Weltmeere. Lünderkundliche Forschung, Festschrift Norbert Krebs, Stuttgart, 347359. 

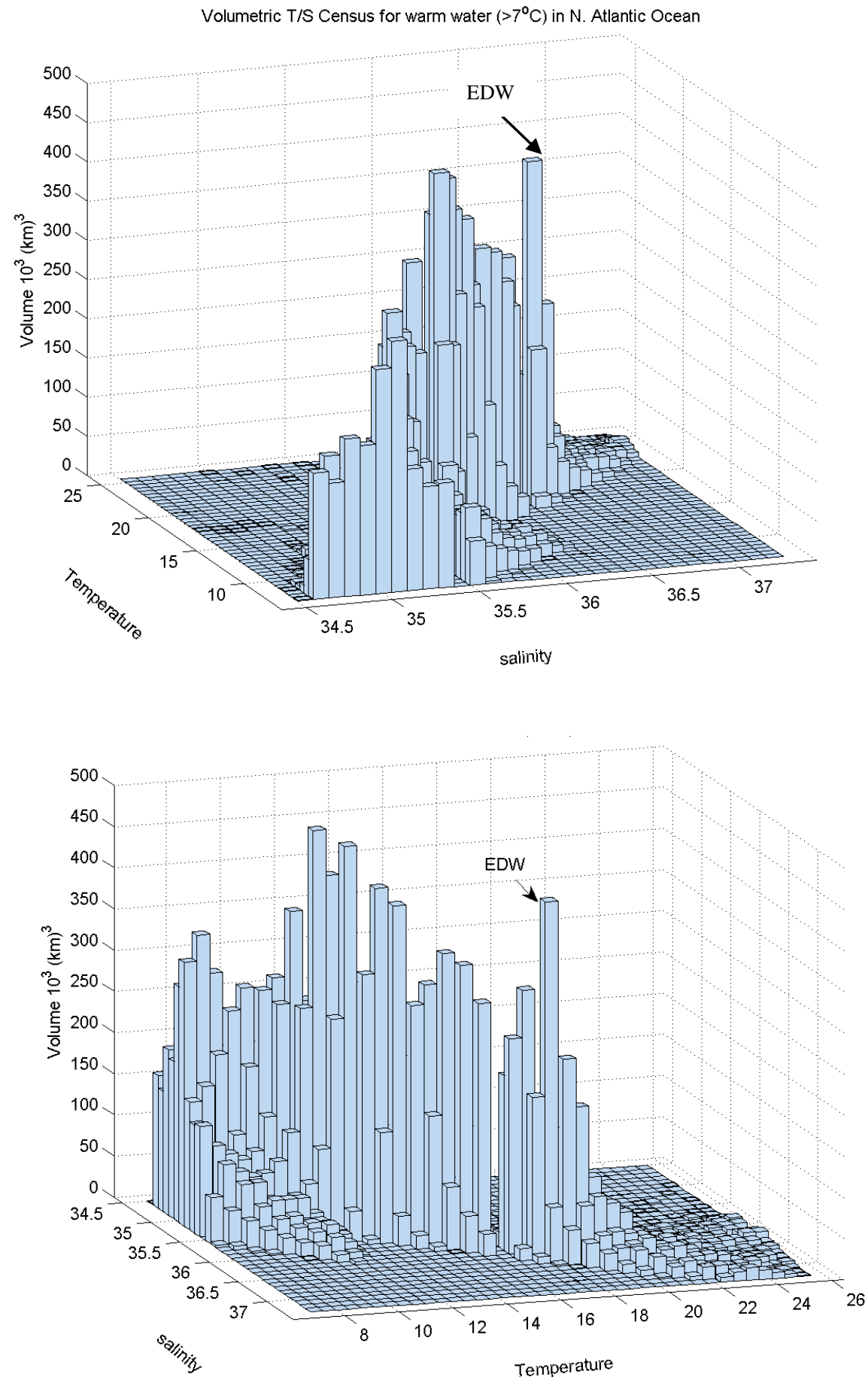

Figure 1. Two different views of a 2D histogram showing the volume (in $10^{3} \mathrm{~km}^{3}$ ) of N. Atlantic waters having temperatures $>7^{\circ} \mathrm{C}$, based on the WOCE Global Hydrographic Climatology (Gouretski and Koltermann, 2004). The total volume of EDW bounded by $\left(36.4-36.6 \mathrm{psu}, 17.5-18.5^{\circ} \mathrm{C}\right)$ is estimated to be $912 \times 10^{3} \mathrm{~km}^{3}$. 

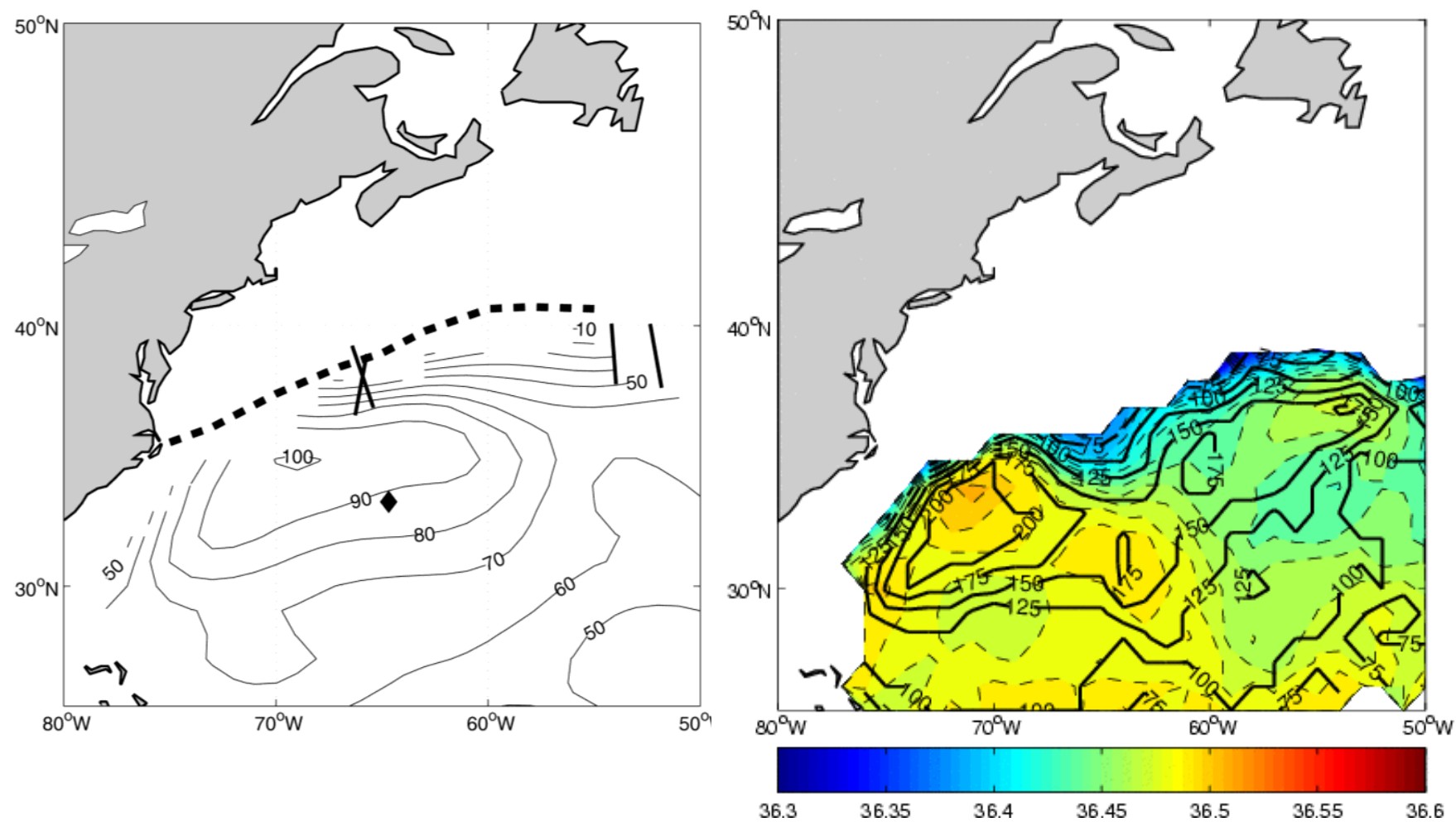

Fig. 2. Left panel: from Kwon and Riser (2004), the geostrophic pressure on the $\sigma_{\theta}=26.5 \mathrm{~kg} \mathrm{~m}^{-3}$ potential density surface (in $\mathrm{cm}$ ) based on mean float velocities is plotted with hydrographic lines from the CLIMODE winter cruise of the Knorr in 2007 (thick black lines), the north wall of the Gulf Stream defined by the $200 \mathrm{~m}$ temperature $=15^{\circ} \mathrm{C}$ from 1955:2008 (heavy dashed line), and the location of Bermuda (black diamond). Right panel: from the WOCE mean climatology, the thickness of the 17.5:18.5 ${ }^{\circ} \mathrm{C}$ temperature surface (solid black contours) has been plotted for all values exceeding $50 \mathrm{~m}$. The color represents the average salinity (psu) in this layer and the contour interval (dashed lines) is 0.01 . The thickness and salinity reveal a climotalogical pattern of EDW variation in the Sargasso Sea. 


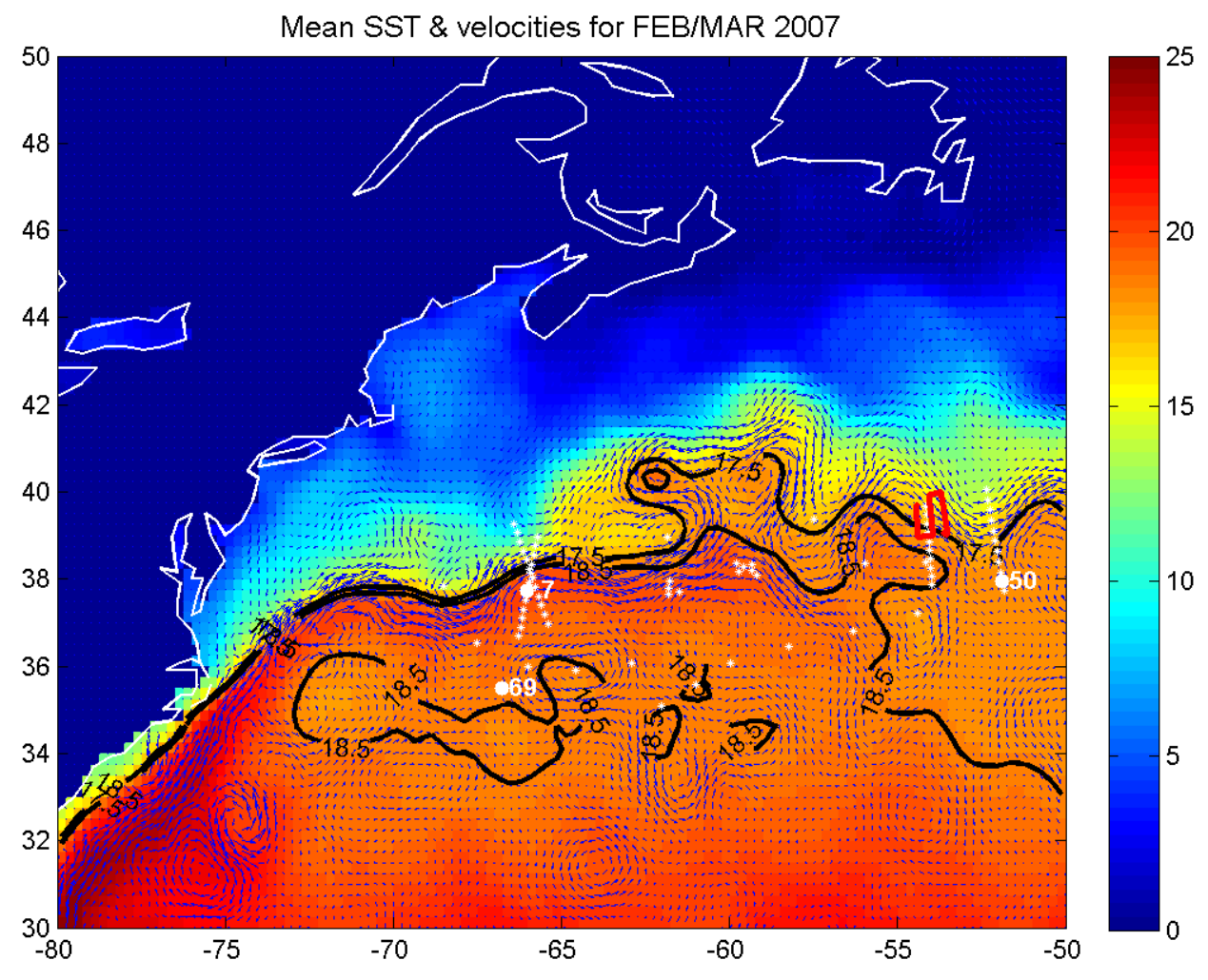

Figure 3. The February/March 2007 mean SST and SSH results with CLIMODE CTD stations (3 selected for Fig. 4). The EDW outcrop region can be seen by the area between the 17.5 and $18.5^{\circ} \mathrm{C} \mathrm{SST}$ contours. The red ladder pattern near $40^{\circ} \mathrm{N}, 54^{\circ} \mathrm{W}$ is from the Seasoar track of Knorr 188, part of which is shown in Fig. 5. 
Knorr 188
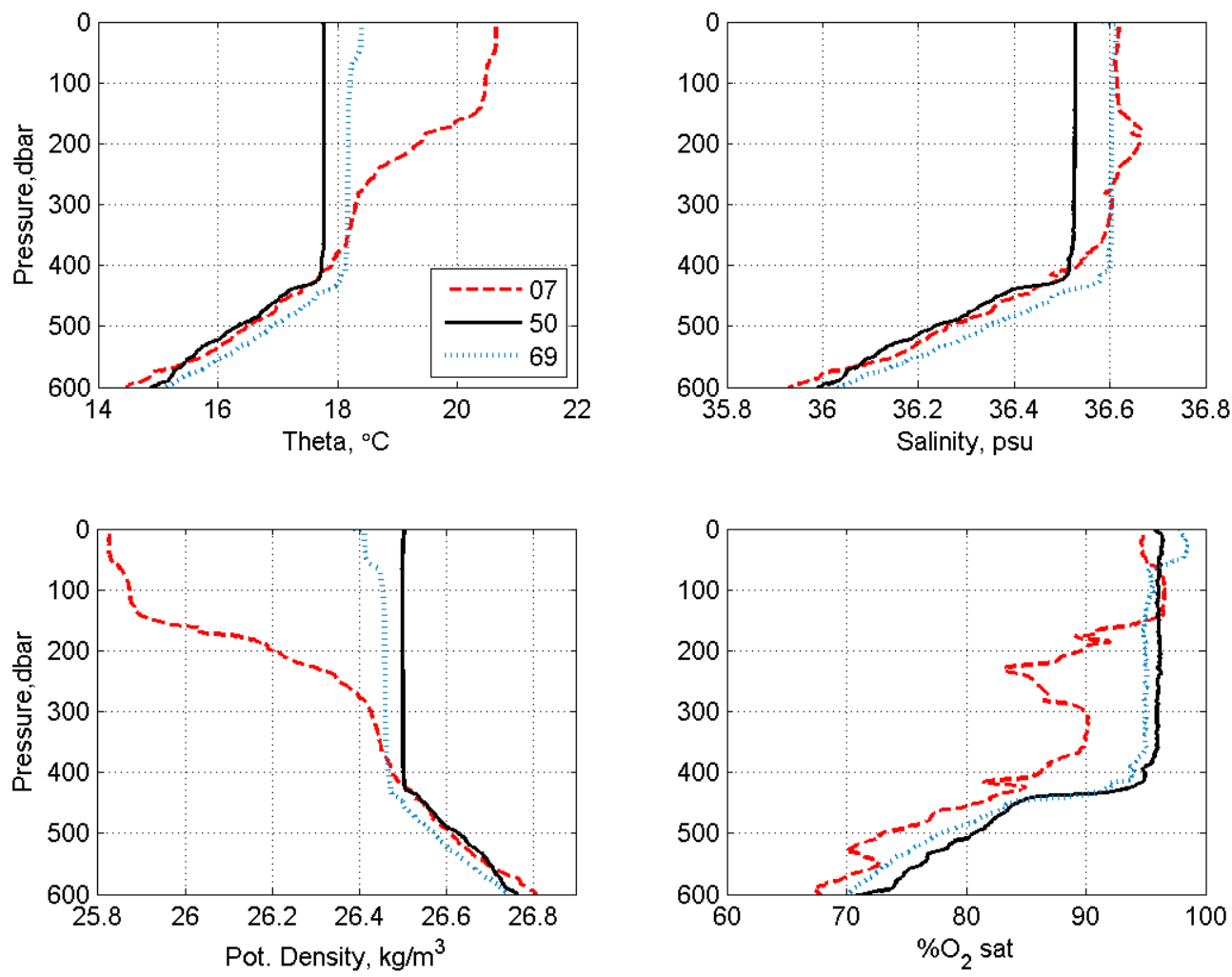

Figure 4. Selected CTD stations from CLIMODE in 2007. Station 7 (red curves) is from the upstream inflow region of the GS just south of the strongest zonal flow. Stations 50 (black line) and 69 (blue dotted line) are from the regions of newly ventilated EDW along the GS front (50) and in the northern Sargasso Sea (69). The four panels show temperature, salinity, potenmtial density, and percent oxygen saturation for the stations. 
SeaSoar section 3; 02/22 04:17 to 02/22 11:40 GMT
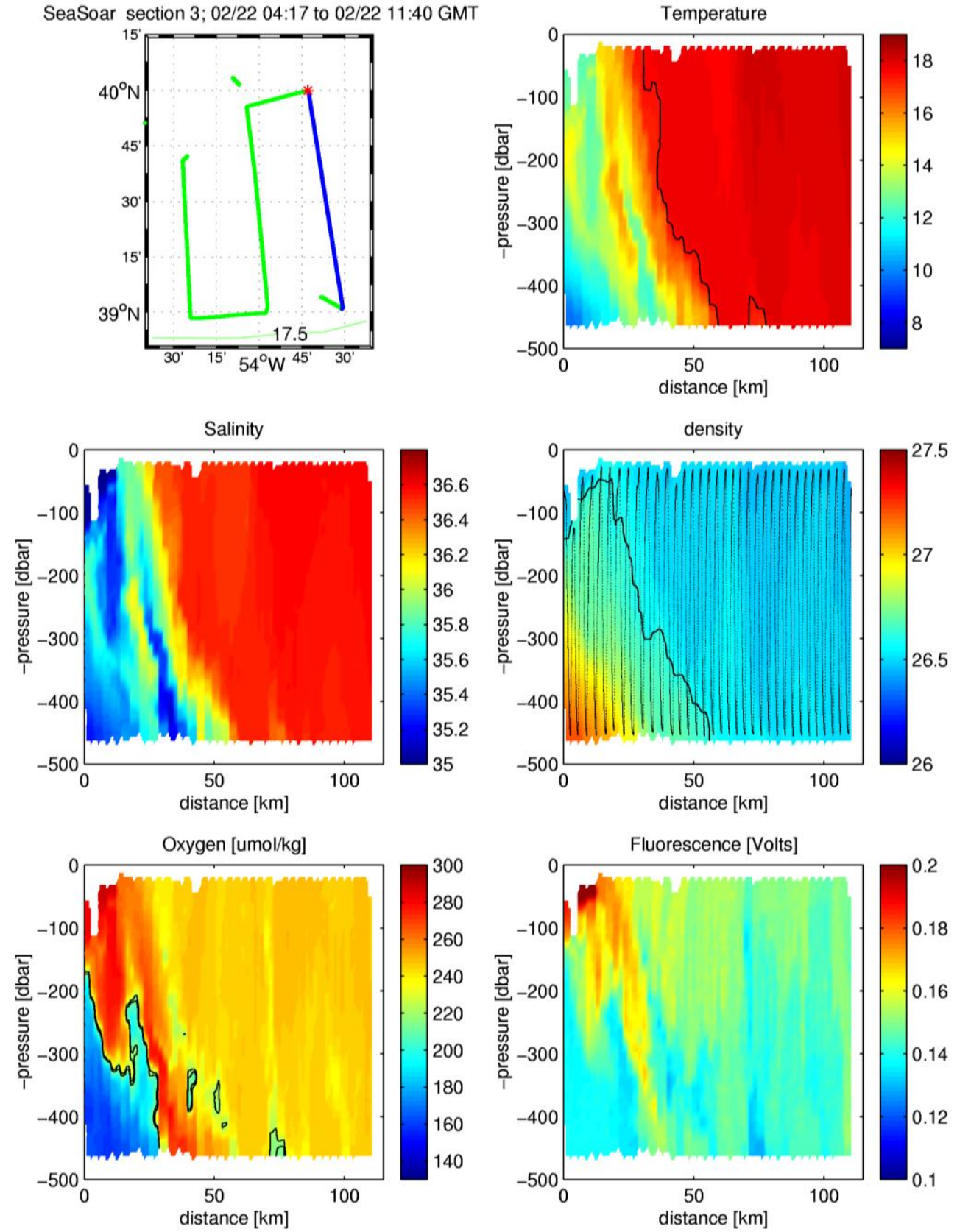

Figure 5. EDW formation within the GS is seen on this Seasoar track (blue line, upper left) with the north on the left hand side of the other panels which show Temperature $\left({ }^{\circ} \mathrm{C}\right.$, upper right), salinity (psu, middle left), $\sigma_{\theta}\left(\mathrm{kg} \mathrm{m}^{-3}\right.$, middle right) with the SeaSoar track shown as thin black lines, dissolved oxygen ( $\mu \mathrm{mol} \mathrm{kg}{ }^{-1}$, lower left), and Chlorophyll fluorescence (uncalibrated volts, lower right). 